\section{Case Reports in Neurology}

Case Rep Neurol 2020;12:466-471

DOI: 10.1159/000511954

Published online: December 11, 2020

(c) 2020 The Author(s)

Published by S. Karger AG, Basel

www.karger.com/crn

This article is licensed under the Creative Commons Attribution 4.0 International License (CC BY) (http://www.karger.com/Services/OpenAccessLicense). Usage, derivative works and distribution are permitted provided that proper credit is given to the author and the original publisher.

\title{
Fragile-X-Associated Tremor/Ataxia Syndrome or Alcohol-Induced Cerebellar Degeneration? A Case Report
}

\author{
Giulia Grigioni $^{\mathrm{a}} \quad$ Christian Saleh $^{\mathrm{b}}$ Phillip Jaszczuk ${ }^{\mathrm{a}} \quad$ Dorothea Wand $^{\mathrm{c}}$ \\ Stefanie Wilmes ${ }^{a}$ Margret Hund-Georgiadis ${ }^{a}$ \\ aREHAB Basel, Clinic for Neurorehabilitation and Paraplegiology, Basel, Switzerland; \\ ${ }^{b}$ Department of Neurophysiology and Neurology, University Hospital Basel, \\ Basel, Switzerland; 'Department of Medical Genetic and Pathology, University Hospital of \\ Basel, Basel, Switzerland
}

\section{Keywords}

Fragile-X-associated tremor $\cdot$ Tremor $\cdot$ Ataxia $\cdot$ Cerebellar atrophy

\section{Abstract}

Fragile-X-associated tremor/ataxia syndrome (FXTAS) is a neurodegenerative disorder that manifests with intention tremor, progressive gait ataxia, and cognitive impairment. The disease is genetically characterized by a premutation of the FMR 1 gene on the X-chromosome manifesting with a CGG triplet expansion between 55 and 200. Given the phenotypical variety of this disease, diagnosis is frequently delayed. We present and discuss a male patient whose diagnosis of FXTAS was delayed due to his concomitant alcohol abuse. 


\section{Case Reports in Neurology}

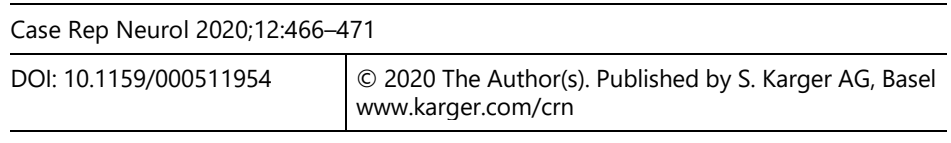

Grigioni et al.: FXTAS and Tremor

\section{Introduction}

Fragile-X-associated tremor/ataxia syndrome (FXTAS; OMIM \#300623) is a neurodegenerative disorder characterized by late-onset progressive gait ataxia, intention tremor, parkinsonism, and cognitive impairment [1]. The penetrance is estimated between $17 \%$ (in male patients aged between 50 and 60 years) and $75 \%$ in patients over 80 years old. The genetic hallmark consists of a premutation of the FMR1 (OMIM \#309550) gene on the X-chromosome manifesting with a CGG triplet expansion between 55 and 200 repeats [1]. As the FMR1 gene is located on the long arm of the X-chromosome, only females can be affected by the disease; male children of affected subjects will not obtain the X-chromosome with the premutation. Therefore, male offspring will not develop FXTAS or fragile-X syndrome (FXS) [2]. The transmission of the X-chromosome with the premutation occurs only to a female offspring, who would be carrier of the affected gene [3]. The risk of a full mutation would present only in the following generation, namely when the female carrier transmits the gene with the premutation to a male offspring; female carries have an increased risk of premature menopause [2].

A triplet repeat greater than 200 results in FXS (OMIM \#300624) [4]. FXS presents with a range of clinical manifestations, such as autism and mental retardation. The diagnosis of FXTAS requires the presence of the premutation and a combination of clinical, radiological and genetic findings. Therapy is supportive [4]. We present and discuss a male patient whose diagnosis of FXTAS was delayed due to his concomitant alcohol abuse.

\section{Case Report}

A 48-year-old male patient with a history of alcohol abuse started to show progressive difficulties walking and a tremor of both hands starting 6 years earlier. Additionally, the patient presented with dysarthria and peripheral neuropathy. Repeated neurological examinations showed a wide-based gait, dysmetria in both upper and lower extremities, intention tremor, and dysdiadochokinesia. The increasing gait difficulties ultimately led to the use of a walking aid. Brain imaging (MRI) showed a mild degree of frontoparietal atrophy as well as diffuse, cerebellar atrophy without signs of Wernicke's encephalopathy (Fig. 1-3). His clinical presentation was repeatedly considered to be alcohol related. In 2010, genetic testing showed a premutation in the FMR1 gene (87 CGG triplets). The testing was carried out because two cousins of maternal origin were diagnosed with FXS. The patient is the only child of two healthy parents. The mother has three siblings, two sisters and one brother, who are all healthy. At age 46, the diagnosis of FXTAS was made and genetic counseling for the patient and his family initiated. The patient has a son who is healthy.

\section{Discussion}

The underlining cause of FXTAS is a genetic disorder in form of a premutation of the Xchromosome expressing itself in a CGG expansion ranging between 55 and 200. A subset of 


\section{Case Reports in Neurology}

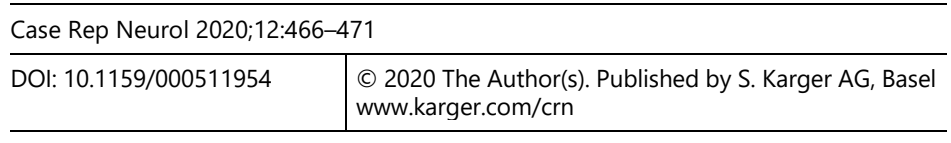

Grigioni et al.: FXTAS and Tremor

patients will develop FXTAS, which is a clinical and radiological diagnosis. Major clinical criteria are intention tremor and gait ataxia, while lesions in the middle cerebellar peduncle ("MCP sign"), corpus callosum and splenium constitute the major radiological diagnostic criteria. An array of motor diseases needs to be considered in the differential diagnosis including Parkinson's disease, multi-system atrophy, essential tremor, and progressive supranuclear palsy [5]. However, as Robertson et al. [5] underline in the differentiation from the aforementioned motor diseases, certain clinical and radiological findings should point the clinician to FXTAS, such as cerebral ataxia/tremor in a patient over 50, the MCP sign, cerebellar atrophy and a family history for genetic diseases [5]. In our patient, tremor, ataxia, CGG expansion as well as the aforementioned radiological findings were present meeting the diagnostic criteria for FXTAS. However, the prompt diagnosis was made difficult and even delayed by the concomitant alcohol abuse by the patient. Differentiation between alcohol-related symptomatology and FXTAS may be clinically and radiologically difficult; alcohol may even accelerate the progression of FXTAS [6, 7]. However, in particular settings, the differentiation between FXTAS and alcohol-induced cerebellar degeneration is academic and the diagnosis of FXTAS should be favored to allow prompt genetic counseling. This is in the patient's best interest because his offspring have a high risk for FXTAS [4].

\section{Conclusion}

FXTAS is a rare disease and, in light of its clinical heterogeneity, may be underrecognized [4]. The clinical and radiological presentation can be confused with multiple other diseases such as multisystem atrophy or alcohol-induced cerebellar degeneration (Table 1). Prompt genetic counseling is paramount for the patient and his/her family. Only a high level of suspicion for FXTAS will allow for diagnosis.

Take-Home Points

- FXTAS is an important differential diagnosis particularly in patients over 60 years old, with tremor, a history of alcohol abuse, PNP, gait instability, and ataxia. Males with the premutation are at highest risk of FXTAS while their daughters will be heterozygous for the premutation [3].

$-40 \%$ of patients with the premutation develop FXTAS and $16-20 \%$ of females are heterozygous for the premutation [3].

- The initial diagnostic workup should include a neurological examination, a full family anamnesis over 3 generations (male members with mental retardation or female members with fragile X-associated primary ovarian insufficiency), and a cranial MRI [3].

- Prompt genetic counseling is paramount [3].

- Treatment is symptomatic (a rehabilitation program should be considered). 


\section{Case Reports in Neurology}

\section{Statement of Ethics}

Written informed consent was obtained from the patient for publication of this case report and any accompanying images.

\section{Conflict of Interest Statement}

The authors declare that they have no conflict of interest.

\section{Founding Sources}

There is no funding source.

\section{Author Contributions}

Giulia Grigioni: Analyzed the data, wrote the draft, and critically revised the final version. Christian Saleh: Analyzed the data, wrote the draft, and critically revised the final version. Phillip Jaszczuk: Wrote the draft and critically revised the final version.

Dorothea Wand: Analyzed the data and critically revised the final version. Stefanie Wilmes: Analyzed the data and critically revised the final version. Margret Hund-Georgiadis: Analyzed the data and critically revised the final version.

\section{References}

1 Jacquemont S, Hagerman RJ, Leehey MA, Hall DA, Levine RA, Brunberg JA, et al. Penetrance of the fragile Xassociated tremor/ataxia syndrome in a premutation carrier population. JAMA. 2004 Jan;291(4):460-9.

2 Hagerman RJ, Leavitt BR, Farzin F, Jacquemont S, Greco CM, Brunberg JA, et al. Fragile-X-associated tremor/ataxia syndrome (FXTAS) in females with the FMR1 premutation. Am J Hum Genet. 2004 May;74(5):1051-6.

3 Hunter JE, Berry-Kravis E, Hipp H, Todd PK. FMR1 Disorders. In: Adam MP, Ardinger HH, Pagon RA, Wallace SE, Bean LJ, Stephens K, et al., editors. GeneReviews((R)). Seattle (WA): University of Washington, Seattle; 1993-2020.

4 Leehey MA. Fragile X-associated tremor/ataxia syndrome: clinical phenotype, diagnosis, and treatment. J Investig Med. 2009 Dec;57(8):830-6.

5 Robertson EE, Hall DA, McAsey AR, O’Keefe JA. Fragile X-associated tremor/ataxia syndrome: phenotypic comparisons with other movement disorders. Clin Neuropsychol. 2016 Aug;30(6):849-900.

6 Seritan AL, Ortigas M, Seritan S, Bourgeois JA, Hagerman RJ. Psychiatric Disorders Associated with Fxtas. Curr Psychiatry Rev. 2013;9(1):59-64.

7 Muzar Z, Adams PE, Schneider A, Hagerman RJ, Lozano R. Addictive substances may induce a rapid neurological deterioration in fragile X-associated tremor ataxia syndrome: A report of two cases. Intractable Rare Dis Res. 2014 Nov;3(4):162-5. 


\section{Case Reports in Neurology}

\begin{tabular}{l|l}
\hline Case Rep Neurol 2020;12:466-471 \\
\hline DOI: 10.1159/000511954 & $\begin{array}{l}\text { (c) 2020 The Author(s). Published by S. Karger AG, Basel } \\
\text { www.karger.com/crn }\end{array}$ \\
\hline
\end{tabular}

Grigioni et al.: FXTAS and Tremor

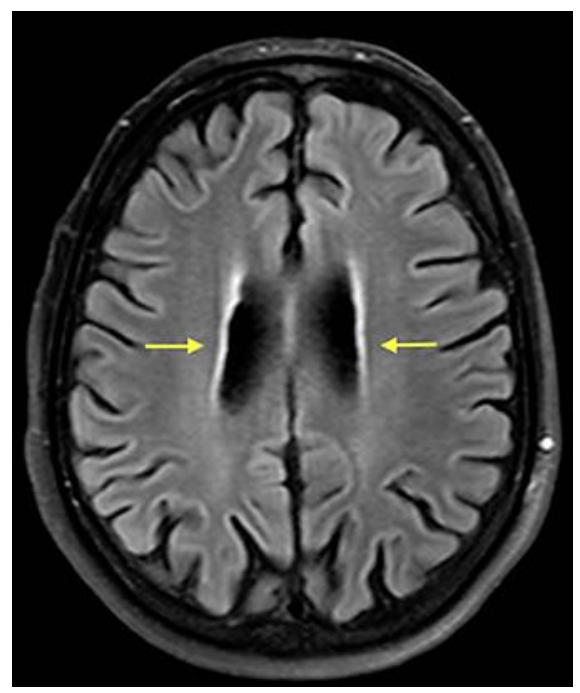

Fig. 1. Cranial FLAIR-MRI: axial view showing periventricular lesions (yellow arrows).

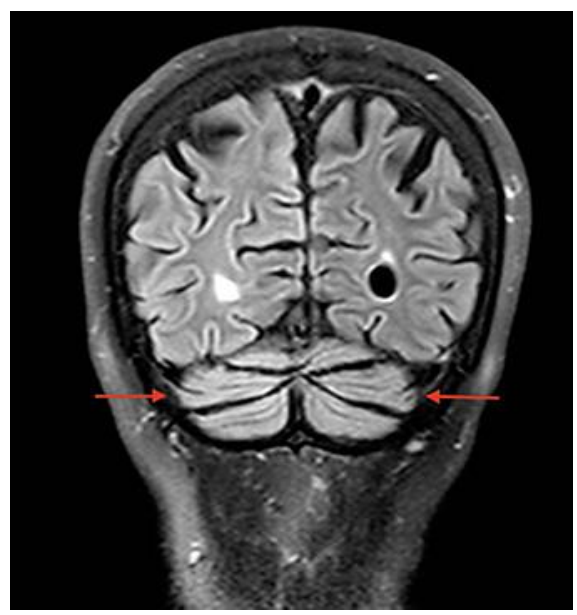

Fig. 2. Cranial FLAIR-MRI: coronal view with cerebellar atrophy (red arrows). 


\section{Case Reports in Neurology}

\begin{tabular}{l|l}
\hline Case Rep Neurol 2020;12:466-471 \\
\hline DOI: 10.1159/000511954 & $\begin{array}{l}\text { (c) 2020 The Author(s). Published by S. Karger AG, Basel } \\
\text { www.karger.com/crn }\end{array}$ \\
\hline
\end{tabular}

Grigioni et al.: FXTAS and Tremor

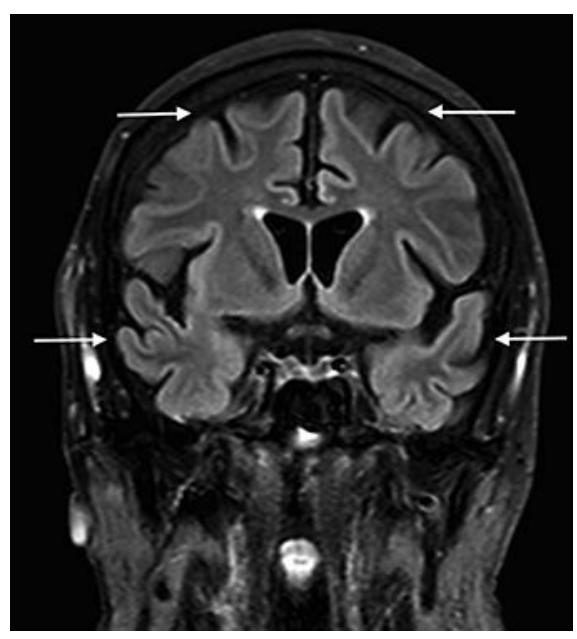

Fig. 3. Cranial FLAIR-MRI: coronal view evidencing frontotemporal atrophy (white arrows).

Table 1. Tremor and cerebellar atrophy: Some common genetic and non-genetic causes

\begin{tabular}{ll}
\hline Disease & Clinic / Comment \\
\hline Alzheimer's disease & Motor symptoms are common in Alzheimer's disease, but tremor is rare \\
\hline Amyotrophic lateral sclerosis & Tremor with upper and lower motor neuron signs \\
\hline Frontotemporal disease & Early cognitive decline, changes in behavior \\
\hline Multisystem atrophy & Tremor tends to be more bilateral with axial and autonomic symptoms \\
\hline Friedreich's ataxia & Onset frequently in childhood, gait ataxia, scoliosis, cardiomegaly \\
\hline Spinocerebellar ataxia & Postural tremor, gait ataxia \\
\hline Multiple sclerosis & Multiple symptoms (e.g., paranesthesia, paresis, ocular symptoms, tremor), transient \\
\hline Alcohol & or fluctuating course, foremost in young females \\
\hline Phenytoin & Anamnesis \\
\hline Cerebellitis & Anamnesis, only by long term use \\
\hline
\end{tabular}

